\title{
Low-cost remotely piloted aircraft system (RPAS) with multispectral sensor for mapping and classification of intertidal biogenic oyster reefs
}

\begin{abstract}
The upsurge in the development of RPAS technology for low altitude remote sensing and miniaturized sensors for enhanced imaging, have led to an increase in marine ecological applications. However, the ubiquity of RPAS with sensors in the visible electromagnetic spectrum may be limiting the applications of fine-scale mapping, monitoring, and identification of biogenic marine habitats along temperate intertidal rocky reefs. Here we used a low-cost RPAS coupled with a multispectral sensor (MicaSense ${ }^{\circledR}$ RedEdge ${ }^{\mathrm{TM}}$ ) and object-based image analysis (OBIA) workflow to produce very high-resolution maps of biogenic oyster reefs in Waitemata Harbour, Auckland, New Zealand. The results show that having spectral bands beyond the visible electromagnetic spectrum gradually enhances feature detection on the imagery and increases the potential to delineate targeted features within a heterogeneous marine ecosystem. Using a rule-based classification technique to extract target features, based on their spectral characteristics following segmentation, yielded an overall accuracy of $83.9 \%$ and a kappa coefficient of $69.8 \%$.Spectral resolution improved for habitat mapping of oyster reefs with additional spectral bands. Highspatial scale monitoring and mapping of turbid exposed intertidal rocky reefs presents unique challenges, but these challenges can be mitigated by targeting flights during ideal meteorological and oceanographic conditions with RPAS
\end{abstract}

Volume 4 Issue 4 - 2020

\author{
Subhash Chand,' Barbara Bollard, ${ }^{2}$ Lennard \\ Gillman ${ }^{3}$ \\ 'PhD Candidate at Institute for Applied Ecology New Zealand, \\ School of Science, Auckland University of Technology, New \\ Zealand \\ ${ }^{2}$ Associate Professor at Institute for Applied Ecology New \\ Zealand, School of Science, Auckland University of Technology, \\ New Zealand \\ ${ }^{3}$ Professor, School of Engineering, Computer \& Mathematical \\ Sciences, Auckland University of Technology, New Zealand
}

Correspondence: Subhash Chand, PhD Candidate at Institute for Applied Ecology New Zealand, School of Science, Auckland University of Technology, Auckland, New Zealand, Tel +64211673840,Email subhash.chand@aut.ac.nz

Received: September 29, 2020 | Published: October I3, 2020

Keywords: oyster reefs, intertidal marine ecosystem, mapping, object-based image analysis (OBIA), rule-based classification, low altitude remote sensing, remotely piloted aircraft system (RPAS)

\section{Introduction}

Shellfish (e.g. oyster reefs) are biogenically structured landscapes and are challenging for manual field surveys. These habitats are economically and ecologically valuable, but they are depleted to numerous anthropogenic and natural hazards. ${ }^{1}$ These habitats can be referred to as "biogenic habitats", formed by plants (e.g. salt marshes, mangroves, seagrass meadows, and kelp forest) and animals (e.g. shellfish) occurring from the intertidal out to the deep ocean. ${ }^{2,3}$ Oyster reefs are a subset of "biogenic habitats" that have hard and rugged structures, sometimes visually imposing, creating a discrete and unique habitat from the surrounding area. ${ }^{4}$ They deliver many ecosystem services to support and protect biodiversity by creating three-dimensional structures, sediment accumulation, nutrient recycling, water filtration and carbon sequestration. All of which are important in the Anthropocene era..$^{5-7}$ Restoration of this resource is of local and global importance and restoration management will require accurate spatial mapping so that ecological status can be monitored.

Recent advances in space-borne (e.g. satellite) and airborne (e.g. manned aerial) imagery have been successful for mapping and assessing the spatial extent of oyster reefs. ${ }^{8,9}$ The increase in spatial $(31 \mathrm{~cm}$, panchromatic and $1.24 \mathrm{~m}$, visible \& near-infrared), spectral resolution ( 8 multispectral) and revisit time $(<1$ day) provided by WorldView- 3/4 satellites has improved the accuracy to capture ecological changes in the dynamic marine environment. ${ }^{10,11}$ However, space-borne imagery is affected by cloud cover and atmospheric aerosol interference, surface reflectance and not always synchronized with desired oceanographic conditions. Consequently, high- resolution imagery often translates into high-costs due to increased storage and processing time taken to orthorectify the imagery to the required accuracy. ${ }^{12}$ According to Digital Globe, the price of a 30$\mathrm{cm}$ georeferenced + natural color or 4-band WorldView 3/4 satellite imagery is approximately $\sim \$ 22.50 \mathrm{USD} / \mathrm{sq} . \mathrm{km}$. Depending on the financial constraints high-resolution imagery may not be easily accessible for all researchers..$^{9,10}$

Mapping biogenic intertidal rocky reefs in temperate waters during high tides is challenging due to turbidity and suspended sediment concentration (SSC), which attenuates light penetration through the water column. ${ }^{13}$ Even with hyper spectral high-resolution data (4.0 $\mathrm{x} 4.0 \mathrm{~m}$ and 126 bands), oysters ( $\sim 15 \mathrm{~cm}$ long) require higher spatial resolution imagery to be effectively detected and mapped, and narrow bands are required to penetrate the water column. ${ }^{13}$ Therefore, for the application of remote sensing techniques to effectively map and detect features, the sensor and platform must be appropriate to the feature being sensed. The issue of spectral band attenuation in the water column and spatial resolution can be solved by surveying intertidal biogenic habitats at low tide.

In Europe, during low tide, researchers successfully classified intertidal biogenic reefs, built by the honeycomb worm, from an RPAS derived multispectral (red-edge (RE) and near-infrared (NIR)) veryhigh-resolution $\left(0.17 \mathrm{~m} /\right.$ pixel) imagery. ${ }^{14}$ Additional spectral bands (e.g. RE and NIR) provided further opportunities to identify and map biogenic habitats based on their spectral characteristics (e.g. water appear dark in NIR band). Another airborne survey of oyster reefs in Rachel Carson Reserve, North Carolina, USA, tested the quality 
of three different RPAS platforms with RGB cameras and ultrahigh resolution $(<5 \mathrm{~cm})$ imagery for mapping and delineating oyster boundaries. ${ }^{11}$ The researchers concluded that RPAS based fieldwork was quicker than traditional fieldwork (e.g. quadrats) and provided a greater number of validation points for accuracy assessment compared to satellite imagery.

For classification of high-resolution (e.g. $<5 \mathrm{~cm} /$ pixel) RPAS imagery, an object-based image analysis (OBIA) performs better than a pixel-based technique (e.g. maximum likelihood) because each pixel is smaller than the feature of interest. ${ }^{15-22}$ The benefit of this technique is its ability to delineate ecological features into meaningful image objects, and to extract spatial, spectral and contextual information from these objects. ${ }^{23,24}$

RPAS in most diverse fields of science has established itself as a new tool, capable of providing unprecedented scientific applications. ${ }^{20,25}$ While recent studies suggested that RPAS may provide better sampling efficiency and data quality for studying intertidal marine ecology, in the visible spectrum. ${ }^{17,20}$ To our knowledge, there are no published studies that have explored the potential of a low-cost RPAS coupled with a multispectral sensor to map and classify biogenic oyster reefs.

Here, we demonstrate the potential of a low-cost RPAS coupled with a miniaturized multispectral sensor (MicaSense ${ }^{\circledR}$ RedEdge ${ }^{\mathrm{TM}}$ ) and use structure from motion photogrammetry to deliver very highresolution maps useable for identification and characterization of biogenic oyster reefs. We show the benefits of enhanced spectral bands for remote sensing of biogenic habitats, and report on time taken and area covered from the RPAS flights. In addition, demonstrate the suitability of RPAS imagery and the accuracy of OBIA combined with rule-based classification for detecting and delineating oyster reefs from a heterogeneous intertidal rocky reef ecosystem.

\section{Materials and methods}

\section{Study site}

The study area for the RPAS survey and mapping of oysters was Meola Reef (Te Tokaroa) in the North Island of New Zealand. Located at $-36.853981 \mathrm{~S}$ and 174.710194E of the Waitemata Harbour in Auckland. This harbor is bordered by New Zealand's major city, Auckland, and it is one of New Zealand's busiest ports. The harbor has been altered by human activities, pollution, urbanization, and it is a hotspot for non-indigenous species. ${ }^{26}$ The Te Tokaroa Meola Reef is a 28,000-year-old basalt volcanic rocky reef that extends over $2 \mathrm{~km}$ into the central Waitemata Harbour. ${ }^{27}$ It is the largest and most visible by satellite (Figure 1) natural rocky reef system in the Waitemata Harbour. ${ }^{28}$ This rocky reef ecosystem supports a high biodiversity of habitats including saltmarsh and mangroves (Avicennia marina) along the landward edge of the reef. ${ }^{29}$ Pacific oysters (Crassostrea gigas) dominate the outer reef and kelp forest dominate the subtidal zone of the reef..$^{27}$ It also provides shelter and a breeding ground for fifty bird species (e.g. black swan, Tui, and South Island Oystercatcher). ${ }^{30}$

The hydrodynamics in this area are controlled by two high $(\sim 1.9$ $-2.9 \mathrm{~m})$ and two low tides ( 0.7- $1.0 \mathrm{~m})$ daily, which flush the harbor from the Hauraki Gulf. ${ }^{27}$ This is a critical process for biogenic benthic ecosystems such as oyster beds and for larvae distribution; tides bring in larvae. This reef structure withstands environmental and human impacts, such as discharge of effluent, trampling while setting fish nets during low tides and shell-fishing, and it is a popular spot for bird watchers, hikers and dog walkers.

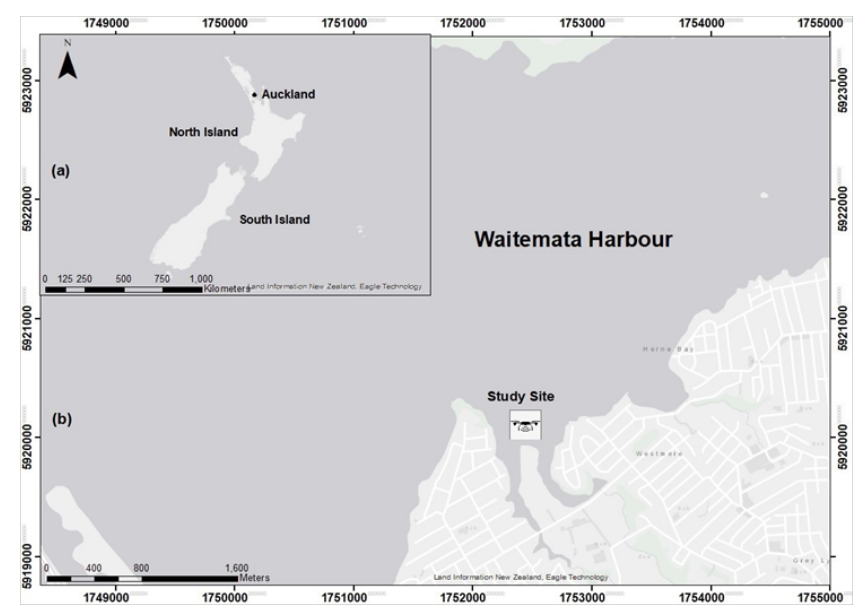

Figure I (a) Location of study site in Auckland, New Zealand. (b) Zoomed-in view of the study area within the Waitemata Harbour.

\section{Flight safety}

Flights were logged on Airshare, ${ }^{32}$ and all were withinthe visible line of sight (VLOS).The pilot was certified with Part 101 RPAS Civil Aviation Authority of New Zealand (CAANZ) and was always accompanied by a trained observer.

\section{Aerial survey data}

The RPAS aerial survey was conducted on 23 March $2019(0.30 \mathrm{~m}$ water level at 16:08 NZST) using a multispectral, MicaSense ${ }^{\circledR}$ RedEdge $^{\mathrm{TM}}$ senor at nadir mounted on a Phantom 4 Pro ${ }^{\circledR}$ multirotor. Pix4D capture ${ }^{\circledR}$ autonomous flight planner was used to plan the fights at $50 \mathrm{~m}$ altitude. The MicaSense ${ }^{\circledR}$ sensor, initially designed for agricultural purposes, leverages a digital RGB DJI camera, 4000 x 3000-pixel imagery, with the following distinct bands: Blue (475 nanometers $(\mathrm{nm}))$, Green $(560 \mathrm{~nm})$, Red $(668 \mathrm{~nm})$, Near IR (840 nm), and Red Edge $(717 \mathrm{~nm})$ and 1280 x 960-pixel imagery. One of the benefits of using this sensor is to perform a radiometric correction during processing in $\mathrm{Pix} 4 \mathrm{D}^{33}$ and using the following equation allows reflectance to be computed for all the bands:

$$
\text { Reflectance }=\frac{\text { Radiance }}{\text { Irradiance }}
$$

The images were stitched and rendered into absolute reflectance maps for each spectral band; pixel values ranged from 0-1.The cost of a consumer grade Phantom 4 Pro RPAS used in this study was 1452.50 NZD (USD 866.70). Flight planning was done using an open-source flight planner, Pix4D capture $\AA$.

\section{Aerial image processing and classification}

\section{Structure from motion photogrammetry}

RPAS aerial images were mosaicked using Pix $4 \mathrm{D}{ }^{\circledR}$ mapper (V 4.4.12 Educational edition). Pix4D ${ }^{\circledR}$ is a professional structure using motion photogrammetry software to transform images into digital spatial models. ${ }^{33}$ Pix $4 \mathrm{D}{ }^{\circledR}$ creates an orthomosaic from geotagged images initially recreating a 3D scene and projecting the orthomosaic to the target coordinate system. Structure from motion (SFM) is a well-established concept for photogrammetry of high-resolution RPAS imagery. ${ }^{20,34,35}$ The general workflow used in Pix4D® includes (1) initial processing, add multispectral imagery to the software, here the algorithm extracts meta-data information from the geotagged photographs (e.g. altitude, camera model, etc.); (2) detect automatic 
tie points between the overlapped images to create a point cloud and mesh; (3) final processing option produces a digital surface model (DSM), orthomosaic and reflectance map of all available bands (only for multispectral) after radiometric processing and calibration. ${ }^{33}$

\section{Geo-reference and radiometric correction}

To geo-reference the orthomosaic accurately, 10 ground control targets were laid out evenly across the study area. These targets were made similar to a section of a checkerboard, printed on an A3 paper and laminated. All targets were surveyed using high accuracy RTKGPS/GNSS (Septentrio $\AA$ ). After initial processing in Pix $4 D \AA$, 3D GCPs were added to improve the accuracy of the project. Radiometric correction information was added from a reflectance panel provided by MicaSense ${ }^{\circledR}$ with calibrated values for each band, added in the final step of processing in Pix $4 \mathrm{D}{ }^{\circledR}$ mapper. This option in Pix $4 \mathrm{D}{ }^{\circledR}$ produces a reflectance map for each band where the value of each pixel represents a true reflectance of the features on the ground.

\section{Image segmentation}

To examine, the potential of high-resolution imagery and accuracy of the OBIA technique to extract targeted features from a heterogeneous ecosystem we decided to use only one RPAS flight This section of the reef is covered with mixed vegetation and oysters are present along the north-west section of the reef. Initially, performed an image segmentation with the Feature Extraction module (FEM) within ENVI ${ }^{\circledR}$ version 5.3 (Exelis Visual Information Solutions, Co, USA). The benefit of this module is that the results of segmentation can be previewed and refined prior to the final segmentation. Following segmentation, attributes/characteristics are calculated for all the objects in the imagery (1) spectral attributes (e.g. mean, standard deviation, maximum \& minimum); (2) texture attributes (e.g. range, mean, variance \& entropy) and (3) fourteen spatial attributes including an adjustable texture kernel size. ${ }^{36}$ Through an iterative process, we found that the optimal segmentation result was achieved at a scale level of 50 (Edge algorithm) and merge level 80 (Full Lambda Schedule). The FEM consisted of two techniques (1) find object (a) segment, (b) merge, (c) refine, (d) compute attributes and (2) extract objects, (a) rule-based classification, (b) exporting results to a shapefile. ${ }^{37}$

\section{Rule-based classification}

ENVI, feature extraction module uses an object-based approach to extract objects with spatial, spectral (brightness and color), and textural characteristics from high-resolution multispectral imagery. The benefit of this module is that multiple objects can be extracted at a time, offers more flexibility in the types of objects being extracted and the classification results can be previewed and further refined through the ENVI Zoom preview portal. ${ }^{37}$ Rules were built for classification based on the object's attributes that were calculated during segmentation and their appearance. The following land cover classes were defined: (1) mangroves and saltmarsh are vegetation that reflects most NIR spectrum, rule assigned using their mean spectral attribute in band 4 (NIR); (2) shadows, bare rocks and sediments appeared very dark in the NIR band, so spectral mean values attributes were used to create a rule for these objects and were merged together; (3) finally, using spatial and spectral attributes of oyster reefs in band 1 (blue), rules were created based on, the mean spectral attribute, pattern of distribution, their shape and appearance (light or dark).

\section{Principles to discriminate oyster rocks}

One of the objectives of this study was to discriminate oyster reefs from multispectral orthomosaics from other land cover features. To achieve this, we capitalized on the spectral reflective properties of different objects on the ground. The following remote sensing principles were followed: (1) most vegetation (mangroves and saltmarsh) absorbs red and blue light for photosynthesis and a plant with chlorophyll reflects near-infrared light, spectral reflectance: 0.47 -1.84 in band 4 (NIR-840nm wavelength). Shadows, bare rock (at a higher elevation than oyster reefs) and sediment (lower elevation than oyster reefs) have dark texture and appearance, spectral reflectance $0.16-0.47$ in band 4 (NIR). Oyster reefs have spectral reflectance: $0.13-0.29$ in band 1 (blue $-475 \mathrm{~nm}$ wavelength).

\section{Accuracy assessment}

For accuracy assessment, used 2,772 random regions of interest (ROI) and an equalized stratified random sampling strategy to create ground truth ROI in the orthomosaic for each class in the total land cover area. The reliability of ground truth points is greater with a high-resolution $(3.5 \mathrm{~cm} /$ pixel $)$ orthomosaic. ${ }^{38}$ Consequently, a confusion matrix was generated, which evaluates the accuracy of the OBIA classification. To assess the accuracy of the final classifications including: (1) overall accuracy from the referenced site what percentage were mapped correctly, (2) kappa coefficient is calculated from a statistical test of the accuracy of a classification, (3) producer's accuracy is the map accuracy from the perspective of a mapmaker; how often real features on the ground are correctly shown on the classified map (4) user's accuracy is the accuracy from the perspective of a map user, often referred as reliability of classification i.e. the classes on a map will actually be present on the ground.

We also conducted an on-foot survey on 2 May 2019, to confirm the visual interpretation of oysters in the land cover from the classification map. For this purpose, we used an eTrex ${ }^{\circledR} 20$ Garmin handheld GPS with a positional accuracy of, $\pm 1-2 \mathrm{~m}$. Along with taking GPS waypoints, a Huawei P30 Pro mobile phone was used to collect geotagged ground photographs. The waypoint and geotagged photos were imported in ArcGIS and projected to WGS 1984 UTM Zone $60 \mathrm{~S}$ datum for visual classification against the classified imagery.

\section{Visual analysis}

To evaluate how RPAS high-resolution imagery can fill the gap in spatial resolution for monitoring marine ecosystems, an RGB (3 band) satellite imagery year 2015 of resolution $75 \mathrm{~cm} /$ pixel was used. ${ }^{28}$ After exploring the archive of LINZ and Auckland Council (sources of imagery in New Zealand) this was the only imagery available at low tide. The spatial accuracy is $\pm 15 \mathrm{~cm}$. Here we zoomed in both imagery until they are blurred to show the scale at which we can view the imagery without any modification or classification.

\section{Results}

\section{Intertidal rocky reef high-resolution orthomosaic}

This study does not distinguish between different types of oysters, including different vertical height and refers to all oyster structures as oyster reefs (including patch and string, clumps of oysters and those attached on mangrove). The most basic need for oyster reef conservation is suitably scaled maps with sufficient information to identify ecological change. ${ }^{39}$ Therefore, to evaluate the potential of a low-cost RPAS with miniaturized multispectral sensor along a rocky intertidal reef, characterized by the presence of oyster reefs, 7 missions were conducted along Meola Reef in Auckland Harbor. Flights were performed between $\sim 9$ to 12 minutes, a total of 18,760 geotagged images were selected after clean-up (involved removing blurred photos before processing) and the total reef area covered was $0.253 \mathrm{Km}^{2}$ (Table 1). The orthomosaics has a spatial resolution of $3.5 \mathrm{~cm} /$ pixel. 
Table I Details of RPAS flights, the area covered, and geotagged photos used for photogrammetry

\begin{tabular}{llll}
\hline Flight number & Time for data capture & Area covered $\left.\mathbf{( K m}^{2}\right)$ & Number of geotagged photos used after clean-up \\
\hline I & I0 minutes & 0.04 & 2840 \\
2 & 10 minutes & 0.033 & 2570 \\
3 & 12 minutes & 0.053 & 2740 \\
4 & II minutes & 0.046 & 3230 \\
5 & 11 minutes & 0.046 & 3520 \\
6 & 10 minutes & 0.035 & 2595 \\
7 & 9 minutes & 0.026 & 1265 \\
& Total & $\mathbf{0 . 2 5 3}$ & $\mathbf{1 8 , 7 6 0}$ \\
\hline
\end{tabular}

The high level of detail in the generated map (Figure 2) clearly shows some important features such as the extent of mangroves and spatial distribution of oyster reefs and provides useful data for mapping and monitoring intertidal biogenic habitats. Indeed, in addition to the dominating features (e.g. mangroves), areas of saltmarsh were clearly distinguishable. Since all the images captured were in the late afternoon, shadows from mangroves were reflected in the northeast direction and had no impact on oyster reefs located in the northwest section.

The segmentation of the orthomosaic is a fundamental step during thematic map production through OBIA since the characteristics of many objects can be used in the classification process. In ENVI, segmentation separates objects into real-world features, and the results from segmentation determine the geometry of objects (Figure 3). Another benefit of using this classification technique is that the final classification results and their associated geometry can be exported as vector shapefiles, which can be subsequently used for other statistical analyses (Figure 4)

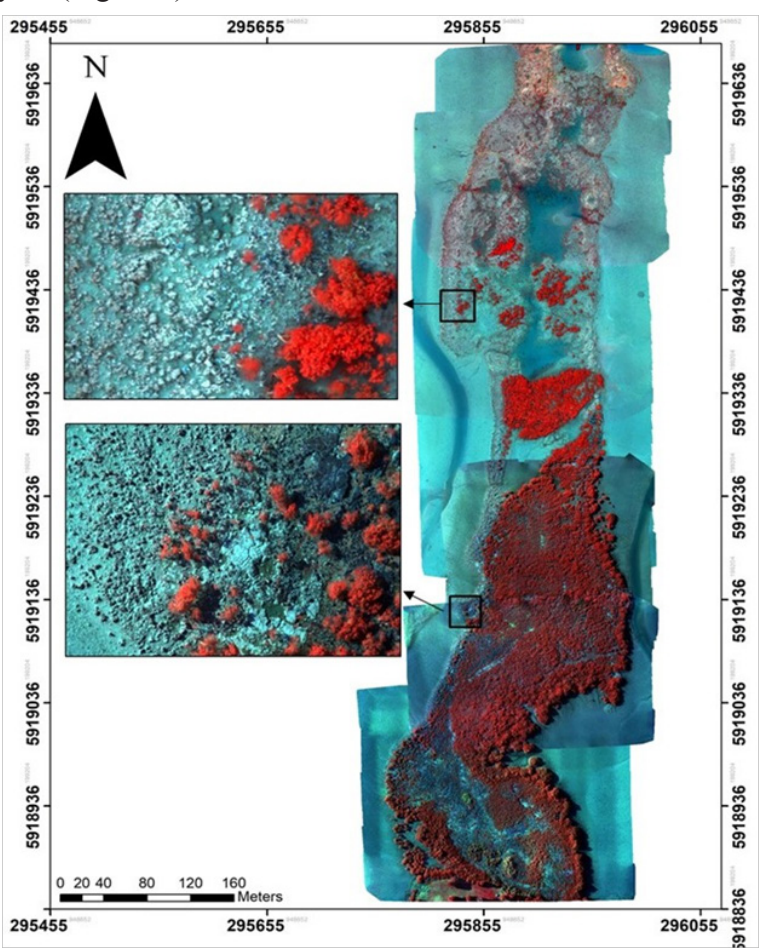

Figure 2 High-resolution false-color orthomosaic $(3.5 \mathrm{~cm} / \mathrm{pixel})$ of Meola Reef. Key features from the land cover are clearly distinguishable from the imagery (e.g. oyster reefs and mangroves).
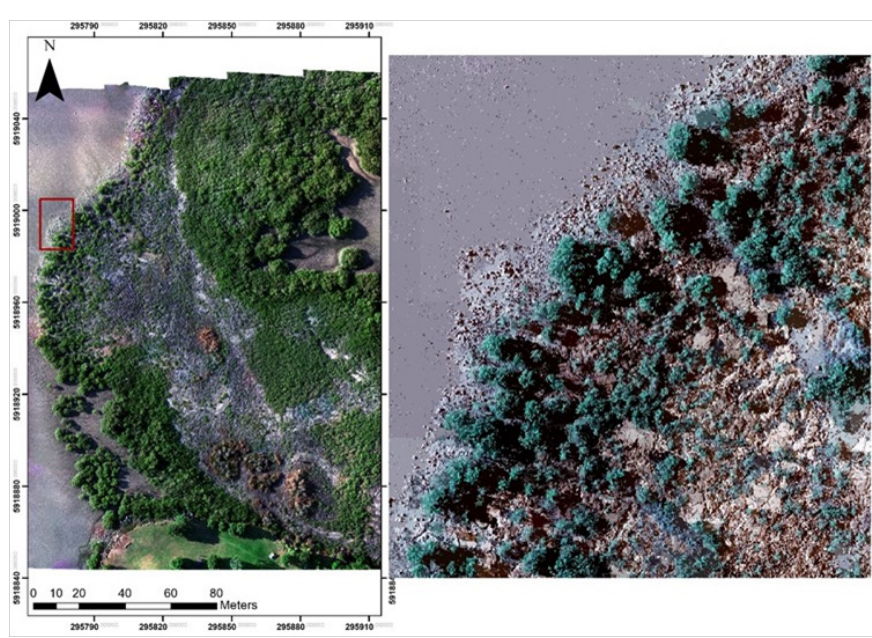

Figure 3 Segmentation results, showing features have been successfully segmented into different real-world (e.g mangrove) objects.

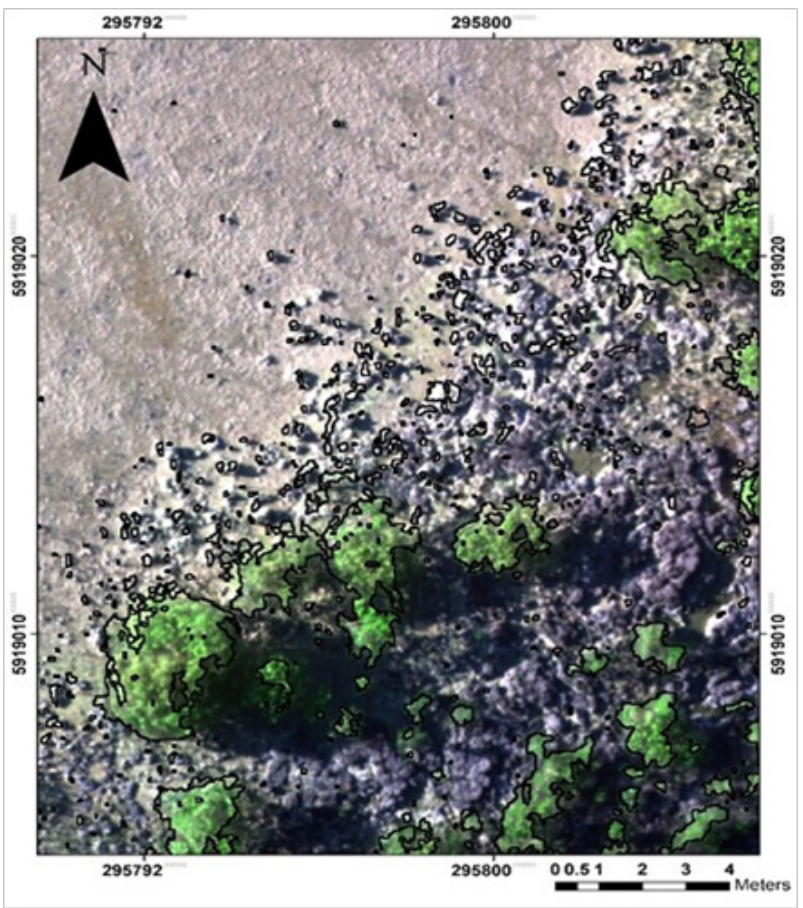

Figure 4 The result of OBIA classification exported as vector shape files with their geometric properties. 


\section{Thematic map}

In this part of the reef, closer to the landward side, thematic map generation to highlight the characteristics of oysters was difficult, due to bird droppings and wet/dry sediments that resembled the spectral properties of oysters. However, despite these limiting factors, satisfactory classification accuracy was achieved following OBIA feature extraction and rule-based classification workflow. A classified map (Figure 5) delineating oysters, demonstrated a good match between the classified land cover and the original RPAS imagery leading to an Overall Accuracy of $83.9 \%$ and a Kappa Coefficient of $69.8 \%$ (Table 2). The Producer's Accuracy for the oyster class was $62.89 \%$ while the User's Accuracy was $95.0 \%$. This means that even though $62.9 \%$ of the reference oyster areas have been correctly identified as "oyster", $95.0 \%$ of the areas identified as "oysters" in the classification were oysters. The reason for this reliability was the contributionof the high-resolution imagery $(3.5 \mathrm{~cm} /$ pixel $)$, enabling oyster reefs to be clearly distinguishable.

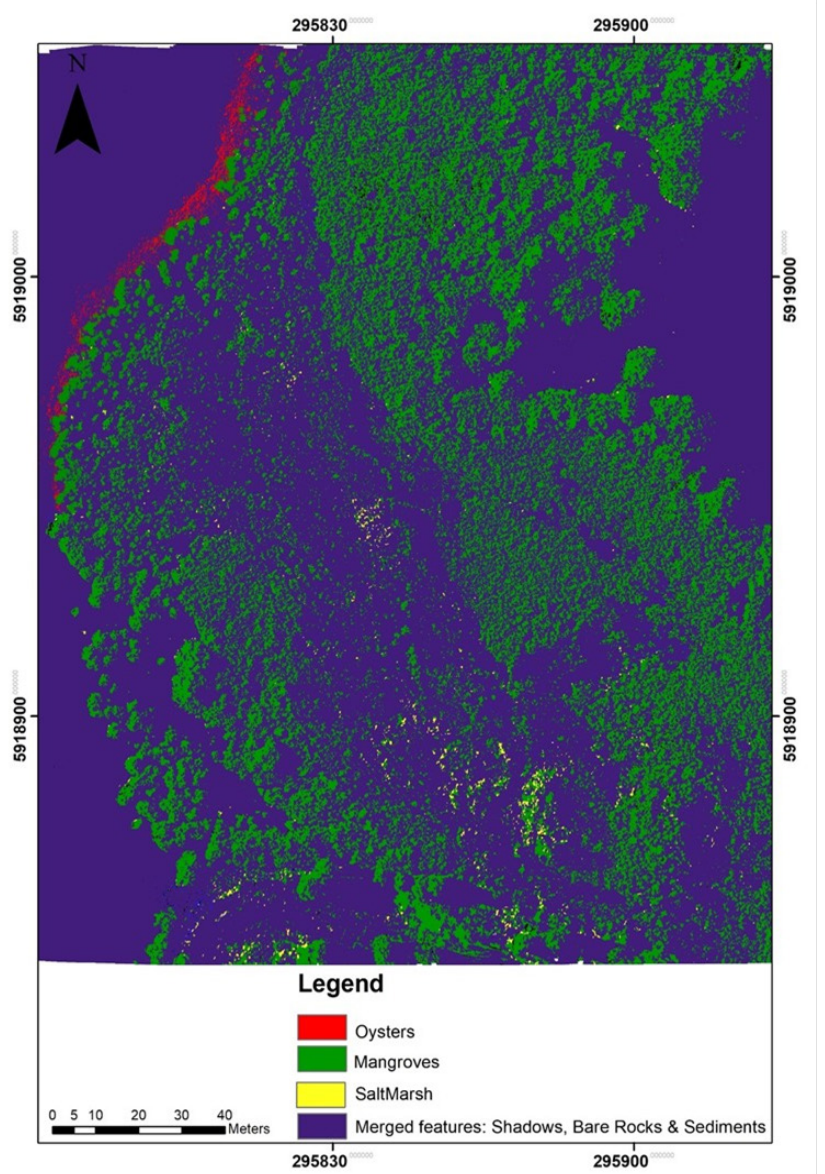

Figure $5 \mathrm{~A}$ high-quality thematic map generated after segmentation and rulebased classification, classified into three main land cover classes.

\section{Visual analysis}

Visual analysis was conducted to examine the potential of RPAS imagery to fill the gap in spatial resolution for remote sensing of oyster reefs. The RPAS imagery has a $3.5 \mathrm{~cm} / \mathrm{pixel}$ resolution and the satellite imagery has a $7.5 \mathrm{~cm} /$ pixel resolution. We interpreted the result using visual cues (e.g. texture, tone, shape, distribution pattern) from both imageries. At a map scale of 1:200 it was difficult to manually digitize and located oysters from the satellite imagery and at 1:100 the image became pixelated (Figure 6A), whereas from the RPAS imagery oysters were evident at a scale of 1:100 (Figure 6B).

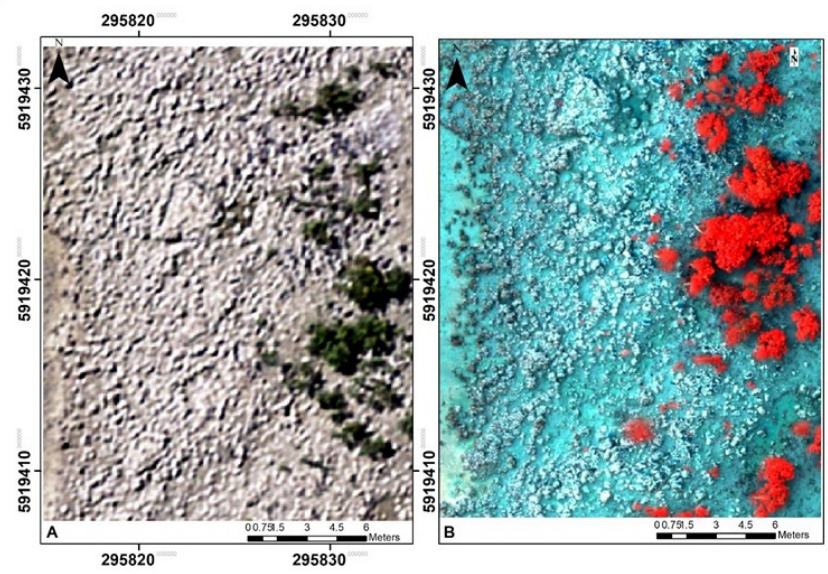

Figure 6 A, Satellite imagery zoomed to a map scale of I: $100^{28}$; B, RPAS imagery zoomed to a map scale of $1: 100$; For visual analysis of remotely sensed oyster reefs.

Table 2 Classified imagery accuracy assessment and absolute accuracy of imagery

\begin{tabular}{|c|c|c|c|c|}
\hline \multicolumn{5}{|c|}{ Classified Imagery } \\
\hline Classes & $\begin{array}{l}\text { Producers } \\
\text { Accuracy } \\
\text { (\%) }\end{array}$ & $\begin{array}{l}\text { User's } \\
\text { Accuracy } \\
\text { (\%) }\end{array}$ & $\begin{array}{l}\text { Overall } \\
\text { Accuracy }\end{array}$ & $\begin{array}{l}\text { Kappa } \\
\text { Coefficient }\end{array}$ \\
\hline Mangrove & 85.85 & 87.62 & & \\
\hline Oysters & 62.89 & 95 & $83.94 \%$ & $69.80 \%$ \\
\hline Saltmarsh & 53.25 & 89 & & \\
\hline $\begin{array}{l}\text { Merged classes } \\
\text { (shadows, } \\
\text { bare rock, and } \\
\text { sediments }\end{array}$ & 100 & 84.98 & & \\
\hline
\end{tabular}

\section{Discussion}

Oysters are fundamental ecosystem engineers, where they also function as nutrient recyclers to filter sediments from water, increasing water clarity to thrive other biogenic habitats (e.g. seagrass). ${ }^{1,40}$ Removing excess nutrients from water is a priority for marine management. ${ }^{3}$ However, once a dominant feature in many temperate marine environments, oyster reefs around the world have shown a marked decline in response to natural (e.g. predation, temperature) and anthropogenic stressors (e.g. sedimentation, housing expansion). ${ }^{1,7}$ While remote sensing (e.g. satellite and aerial imagery) in the marine environment is usually difficult to target optimum tidal and meteorological conditions, the availability of RPAS as a survey tool has met this need. ${ }^{17,20}$ For marine ecological research, RPAS connects the difference between satellites and high-resolution ground surveys. ${ }^{42,43}$ However, ground surveys have a limited window of time for sampling between tides and can be destructive (e.g. trampling) to biodiversity. Our result from RPAS derived imagery produced highresolution orthomosaic with a ground sampling distance of $3.5 \mathrm{~cm} /$ pixel, were captured within a smaller time-frame $(\sim 10$ minutes flight time) and were obtained in a non-destructive manner.

High spatial and temporal resolution using low altitude remote sensing with multispectral RPAS has the benefit of being able to 
detect changes preceding ecological collapse (e.g. tipping points).$^{39}$ In the past, researchers have conducted manual ecological field surveys using quadrat sampling on reefs. ${ }^{27}$ Between 2001 and 2017 , Pacific oysters (Crassostrea gigas), and New Zealand rock oysters (Saccostrea glomerate) were the most abundant species on the reef. However, a subsequent increase in the population of predatory oyster borer snails has reduced the population of both species of oysters..$^{26,27,29}$ Although in this study we evaluated the potential of a multispectral sensor coupled with a low-cost RPAS from a $50 \mathrm{~m}$ altitude, future studies can use this technique to monitor and map the distribution of predatory borer snails from an altitude of $\sim 20-30 \mathrm{~m}$. A lower flying altitude would improve the detail provided for directing mitigation measures or eradication of the predators.

Our results validated that RPAS platforms as a useful tool for the identification of intertidal marine biogenic habitats. ${ }^{20,35,44}$ To our knowledge, this is the first time multispectral sensors coupled with RPAS for high-resolution have been used to map oysters in temperate marine environments. In this study, a high resolution $(3.5 \mathrm{~cm} / \mathrm{pixel})$ multispectral orthomosaic demonstrated that the use of spectral bands beyond the visible electromagnetic spectrum enhanced feature detection and increased the ability to delineate targeted features within a heterogeneous marine ecosystem. In temperate marine environments, turbidity and SSC usually make remote sensing of marine habitats difficult. ${ }^{45}$ To overcome this, we used RPAS on-demand capability to capture targeted habitats at low tide and at optimum meteorological conditions. Although data capture was after the solar noon, the flights were planned so that shadows from vegetation had no impact on the targeted feature, oyster reefs.

To maintain biodiversity, pivotal habitats such as oyster reefs that provide quality breeding and feeding grounds for many fish and bird species need to be protected. ${ }^{7}$ This research showed that high-resolution RPAS derived imagery and OBIA with a rulebased classification (based on spectral attributes of target features) has the potential to accurately delineate targeted features within a heterogeneous marine ecosystem. The results from segmentation of different features, such as oysters and mangroves, can be exported as vector shapefiles and used for other geo-analytics. RGB camera images are often good for revealing where a feature is on the ground, whereas the multispectral imagery allowed us to capture a target's reflectance from each wavelength (e.g. RedEdge and NIR) for enhanced target discrimination. This can be explored in future studies to classify oyster reefs into more categories including: shell density, mean size, alive versus dead (because dead oysters are more reflective), reef complexity and oyster species.

\section{Conclusion}

As anthropogenic impacts including climate change continue to exert pressure on marine biogenic habitats, innovative methods for deriving useful information from multiple remote sensing imagery will be increasingly useful as a tool to monitor this change. The technologies we have deployed in this study will be able to provide a critical source of information to marine managers for conservation and planning. RPAS remote sensing enables the conduct of surveying on-demand during low tides and over a broad spatial scale. Flying low enables the capture of high-resolution imagery ranging from 50 to $4 \mathrm{~mm}$. Despite limitations for classifying features of similar spectral reflectance OBIA for segmentation with a rule-based classification was sufficient for object identification and delineation of oyster reefs from other habitats. Our study showed that the deployment of RPAS coupled with a multispectral sensor for mapping and identification of oyster reefs in a heterogeneous marine environment greatly increased the classification accuracy. Overall accuracy of $83.9 \%$ and a Kappa Coefficient of $69.8 \%$ was achieved. Our method enables long-term monitoring of marine environments at lower cost to ground-based methods, at higher accuracy to other remote sensing methods and is therefore a valuable tool for conservation and restoration management.

\section{Acknowledgments}

We acknowledge Mr. Ashray Doshi, the chief pilot at Auckland University of Technology for providing RPAS for this project. We also acknowledge Ms. Kavita Devi Prasad for her assistant during fieldwork and her continuous support during this project. We also like to acknowledge Professor Len Gillman of School of Science at Auckland University of Technology for providing his expert contribution in editing this paper.

\section{Conflicts of interest}

The authors declare no conflict of interest.

\section{References}

1. Grabowski JH, Brumbaugh RD, Conrad RF, et al. Economic valuation of ecosystem services provided by oyster reefs. Bioscience. 2012;62(10):900-909.

2. Butchart SHM, Walpole M, Collen B, et al. Global Biodiversity: Indicators of Recent Declines. Science. 2010;328(5982):1164-1168.

3. Newell RIE, Koch EW. Modelling seagrass density and distribution in response to changes in turbidity stemming from bivalve filtration and seagrass sediment stabilization. Estuaries. 2004;27:793-806.

4. Kellogg ML, Smyth AR, Luckenbach MW, et al. Use of oysters to mitigate eutrophication in coastal waters. Estuarine, Coastal and Shelf Science. 2014;151:156-168.

5. Halpern BS, Walbridge S, Selkoe KA, et al. A global map of humanimpact on marine ecosystems. Science. 2008;319(5865):948-952.

6. Beck MW, Brumbaugh RD, Airoldi L, et al. Shellfish at risk: A global analysis of problems and pollutions. The Nature Conservancy, Arlington VA, 52. ISPRS Ann. Photogramm. Remote Sens Spat Inf Sci. 2012;4:101-106.

7. Thorngren L, Holthuis TD, Lindegarth S, et al. Developing methods for assessing abundance and distribution of European oysters (Ostrea edulis) using towed video. PLoS One. 2017;12(11):1-20.

8. Grizzle RE. Distribution and abundance of (Crassostrea virginica) (Gmelin,1791) (Eastern oyster) and (Mercenaria spp. (Quahogs) in a coastal lagoon. Journal of Shellfish Research. 2002;9(2):347-358.

9. NOAA Coastal Services Center. Pilot investigation of remote sensing for intertidal oyster mapping in coastal South Carolina: a methods comparison NOAA coastal services center noaa / csc / 20514-pub. Methods; 2003. 1-32 p.

10. Reshitnyk L, Costa M, Robinson CLK, et al. Evaluation of WorldView-2 and acoustic remote sensing for mapping benthic habitats in temperate coastal pacific waters. Remote Sensing of Environment. 2014;153:7-23.

11. Schwantes A, Poulin S, Johnston D, et al. Integrating Drone Imagery into High Resolution Satellite Remote Sensing Assessments of Estuarine Environments. Remote Sensing. 2018;10(8):1257.

12. Schill SR, Porter D, Coen LD, et al. Development of an Automated Mapping Technique for Monitoring and Managing Shellfish Distributions. NOAA/UNH Cooperative Institute for Coastal and Estuarine Environmental Technology (CICEET): Durham NH; 2006. $88 \mathrm{p}$. 
13. Casella E, Collin A, Harris D, et al. Mapping coral reefs using consumergrade drones and structure from motion photogrammetry techniques. Coral Reefs. 2017;36(1):269-275.

14. Collin A, Dubois S, James D, et al. Improving Intertidal Reef Mapping Using UAV Surface, Red Edge, and Near-Infrared Data. Drones. 2019;3(3):67.

15. Roelfsema CM, Lyons M, Kovacs EM, et al. Mapping of seagrass cover species and biomass: a semi-automated object-based image analysis approach. Remote Sens Environ. 2014;150:172-187.

16. Roelfsema C, Kovacs E, Ortiz JC, et al. Coral reef habitat mapping: A combination of object-based image analysis and ecological modelling. Remote Sensing of Environment. 2018;208:27-41.

17. Nahirnick NK, Reshitnyk L, Campbell M, et al. Mapping with confidence, delineating seagrass habitats using Unoccupied Aerial Systems (UAS). Remote Sens Ecol Conserv. 2019;5(2):121-135.

18. Ventura D, Jona Lasinio G, Ardizzone G. Temporal partitioning of microhabitat use among four juvenile fish species of the genus Diplodus (Pisces: Perciformes, Sparidae). Mar Ecol. 2015;36(4):1013e1032.

19. Ventura D, Bruno M, Jona Lasinio G, et al. A low-cost drone-based application for identifying and mapping of coastal fish nursery grounds. Estuarine, Coastal and Shelf Science. 2016;171:85-98.

20. Ventura D, Bonifazi A, Gravina MF, et al. Mapping and classification of ecologically sensitive marine habitats using unmanned aerial vehicle (UAV) imagery and Object-Based Image Analysis (OBIA). Remote Sensing. 2018;10(9):1-23.

21. Chabot D, Dillon C, Shemrock A, et al. An Object-Based Image Analysis Workflow for Monitoring Shallow-Water Aquatic Vegetation in Multispectral Drone Imagery. ISPRS International Journal of GeoInformation. 2018;7(8):294.

22. Dronova I. Object-based image analysis in wetland research: A review. Remote Sensing. 2015;7(5):6380-6413.

23. Blaschke T. Object Based Image Analysis for Remote Sensing. J Photogramm Remote Sens. 2010;65(1):2-16.

24. Horning N. Land cover classification methods, Version 1.0. American Museum of Natural History, Centre for Biodiversity and Conservation; 2004.

25. Manfreda S, McCabe MF, Miller PE, et al. On the Use of Unmanned Aerial Systems for Environmental Monitoring. Remote Sens. 2018;10(4):641.

26. Hayward BW. Introduced marine organisms in New Zealand and their impact in the Waitemata Harbor, Auckland. Tane. 1997;36:197-223.

27. Foley MM, Shears NT. Te Tokaroa Meola Reef intertidal reef ecological monitoring programme: 2001 to 2017. Auckland Council technical report, TR2019/004; 2019
28. Auckland 0.075m Urban Aerial Photos (2015-2016). Download from Land Information New Zealand

29. Hayward BW, Grenfell HR, Reid C, et al. Recent New Zealand shallow water benthic foraminifera - taxonomy, ecologic distribution, biogeography and use in paleoenvironmental assessment. Institute of Geological \& Nuclear Sciences Monograph 21; 1999.

30. New Zealand eBird; 2019.

31. Pix4D Radiometric correction documentation (2011-2020).

32. Airshare.

33. Pix4D.

34. Johnston DW. Unoccupied Aircraft Systems in Marine Science and Conservation. Annual Review of Marine Science. 2018;11(1):439-463.

35. Murfitt SL, Allan BM, Bellgrove A, et al. Applications of unmanned aerial vehicles in intertidal reef monitoring. Sci Rep. 2017;7:10259.

36. Warner T. Kernel-based texture in remote sensing image classification. Geogr Compass. 2011;5(10):781-798.

37. ENVI Zoom Tutorial: ENVI Feature Extraction with Rule-Based Classification. (n.d)

38. Lechner AM, Fletcher A, Johansen K, et al. Characterising Upland Swamps Using Object-Based Classification Methods and Hyper-Spatial Resolution Imagery Derived from an Unmanned Aerial Vehicle; 2012

39. Gomes I, Peteiro L, Bueno-Pardo J, et al. What's a picture really worth? On the use of drone aerial imagery to estimate intertidal rocky shore mussel demographic parameters. Estuarine, Coastal and Shelf Science. 2018;213:185-198.

40. Newell RIE, Fisher TR, Holyoke RR, et al. Influence of eastern oysters on nitrogen and phosphorus regeneration in Chesapeake Bay, USA. in RF Dame and S Olenin, editors. The Comparative Roles of Suspension Feeders in Ecosystems. Springer, Netherlands; 2005.

41. Klemas VV. Remote Sensing of Submerged Aquatic Vegetation. In: Finkl C, Makowski C. (eds) Seafloor Mapping along Continental Shelves. Coastal Research Library, vol 13. Springer: Cham; 2016.

42. Anderson K, Gaston KJ. Lightweight unmanned aerial vehicles will revolutionize spatial ecology. Front Ecol Environ. 2013;11(3):138-146.

43. Chand S, Bollard B, Prasad DK. Bridging the gap between highaltitude remote sensing and ground survey for sampling in the marine environment; 2019.

44. Konar B, Iken K. The use of unmanned aerial vehicle imagery in intertidal monitoring. Deep-Sea Research Part II: Topical Studies in Oceanography. 2018;147:79-86.

45. Nagelkerken I, Sheaves M, Baker R, et al. The seascape nursery: anovel spatial approach to identify and manage nurseries for coastal marine fauna. Fish Fish Oxf. 2015;16(2):362-371. 